(2) Open Access Full Text Article

\title{
Comparison of self-reported quality of vision outcomes after myopic LASIK with two femtosecond lasers: a prospective, eye-to-eye study
}

This article was published in the following Dove Press journal:

Clinical Ophthalmology

I September 2016

Number of times this article has been viewed

\author{
Christopher S Sáles' \\ Edward E Manche ${ }^{2}$ \\ 'Weill Cornell Medical College, New \\ York, NY, USA; 'B Byers Eye Institute, \\ Stanford University School of \\ Medicine, Palo Alto, CA, USA
}

Purpose: To compare self-reported quality of vision (QoV) outcomes after myopic LASIK (laser-assisted in situ keratomileusis) with two femtosecond lasers.

Design: Prospective, randomized, eye-to-eye study.

Methods: Consecutive myopic patients were treated with wavefront-guided LASIK bilaterally. Eyes were randomized according to ocular dominance. The flap of one eye was made with the IntraLase FS $60 \mathrm{kHz}$ femtosecond laser with a conventional $70^{\circ}$ side-cut, and the flap of the fellow eye was made with the IntraLase iFS $150 \mathrm{kHz}$ femtosecond laser with an inverted $130^{\circ}$ side-cut. Patients completed the validated, Rasch-tested, linear-scaled 30-item QoV questionnaire preoperatively and at Months 1,3, 6, and 12 .

Results: The study enrolled 120 fellow eyes in 60 patients. None of the measured QoV parameters exhibited statistically significant differences between the groups preoperatively or at any postoperative time point.

Conclusion: Creating LASIK flaps with an inverted side-cut using a $150 \mathrm{kHz}$ femtosecond laser and with a conventional $70^{\circ}$ side-cut using a $60 \mathrm{kHz}$ femtosecond laser resulted in no significant differences in self-reported QoV assessed by the QoV questionnaire.

Keywords: quality of vision, femtosecond, LASIK, wavefront-guided, myopia

\section{Introduction}

Since their commercial introduction in the early 2000 s, femtosecond lasers have become increasingly more sophisticated in how they deliver photodisruptive energy to create a LASIK (laser-assisted in situ keratomileusis) flap. The first commercially available system delivered pulses at a rate of $6 \mathrm{kHz}$, which required a relatively large spot size and a high energy level per pulse. Subsequent systems introduced 10, 15, 30, 60, $150 \mathrm{kHz}$, and even higher frequencies. Higher frequencies permitted smaller spot sizes and lower pulse energies. In addition to the obvious benefits of shorter suction times, faster lasers offered the prospect of a "cleaner cut", including the promise of less inflammation caused by laser-related tissue necrosis and a smoother interface. ${ }^{1-3}$ Advancements in laser technology also ushered in the possibility of more sophisticated side-cut architecture.

The IntraLase FS 60 kHz system (Abbott Medical Optics, Santa Ana, CA, USA) is a femtosecond laser commonly used for flap creation in LASIK. Its successor is the IntraLase iFS $150 \mathrm{kHz}$, which in addition to being faster - taking about 12 seconds to cut a $9 \mathrm{~mm}$ flap compared to 30 seconds - is also capable of making flaps with an inverted side-cut up to an angle of $150^{\circ}$. By comparison, the IntraLase FS $60 \mathrm{kHz}$ cuts flaps at a conventional $70^{\circ}$ angle (Figure 1). 


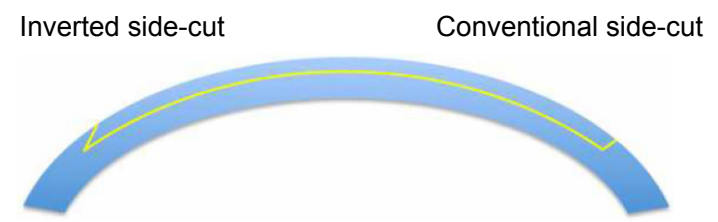

Figure I Schematic of inverted, left, vs conventional, right, side cut LASIK flaps. Abbreviation: LASIK, laser-assisted in situ keratomileusis.

Only a few studies have compared the faster speed and advanced side-cut architecture offered by the iFS 150 $\mathrm{kHz}$ system to the popular FS $60 \mathrm{kHz}$ system, but none of them have analyzed self-reported quality of vision (QoV) outcomes. Contralateral comparison of the two systems has shown that the iFS $150 \mathrm{kHz}$ laser yields faster recovery of uncorrected distance visual acuity (UDVA) at 1 week, but equivalent UDVA compared to the FS $60 \mathrm{kHz}$ at 1 year. ${ }^{4}$ The iFS $150 \mathrm{kHz}$ has also been shown to provide faster recovery of corneal sensation with a $130^{\circ}$ inverted side-cut compared to the FS-60's conventional side-cut; however, dry eye symptoms showed no statistically significant difference between the groups. ${ }^{5}$

\section{Methods}

In this prospective, randomized, eye-to-eye study, we compare the $150 \mathrm{kHz}$ and $60 \mathrm{kHz}$ laser systems in contralateral eyes with myopia. The primary outcome measure at Months $1,3,6$, and 12 was self-reported QoV measured by the validated 30-point QoV ${ }^{6}$ questionnaire.

This prospective, comparative study adhered to the tenets of the Declaration of Helsinki as well as the Health Insurance Portability and Accountability Act and was conducted at the Stanford Eye Laser Center after receiving Stanford University Institutional Review Board approval. All patients provided their written informed consent after full disclosure of the nature of the research.

A computer-generated randomization schedule was used to assign the dominant eye to have LASIK flap creation with either the $60 \mathrm{kHz}$ IntraLase FS or the $150 \mathrm{kHz}$ IntraLase iFS. The fellow eye was treated with the alternative femtosecond laser.

Inclusion criteria were a stable refraction with a change of less than 0.50 diopters (D) of sphere or cylinder in the last year, discontinuation of soft contact lens wear at least 1 week before the preoperative evaluation, best-corrected visual acuity of 20/20 or better, age older than 21 years, and ability to participate in postoperative examinations for at least 12 months.

Exclusion criteria included use of rigid gas permeable contact lenses, severe dry eye or blepharitis, corneal pathology (ie, recurrent erosion syndrome, basement membrane disease, keratoconus, and irregular corneal mires on central keratometry), pachymetry whereby the postoperative thickness would be less than $250 \mu \mathrm{m}$ below the flap, baseline standard manifest refraction with a difference of $0.75 \mathrm{D}$ or more in sphere power or $0.50 \mathrm{D}$ in cylinder power as compared to the baseline standard cycloplegic refraction, history of herpes zoster or herpes simplex, corneal warpage (ie, contact lensinduced topographical abnormalities), and certain systemic diseases or conditions (ie, connective tissue disease, diabetes, pregnancy, lactation, immunocompromised state, and severe atopy). Also excluded were patients with sensitivity to the study's concomitant medications and patients participating in a clinical trial for another ophthalmic drug or device.

Patients meeting these criteria underwent a comprehensive preoperative evaluation, including history, manifest, and cycloplegic refraction using the Early Treatment Diabetic Retinopathy Study charts, 5\% and 25\% contrast sensitivity (Precision Vision, La Salle, IL, USA), slit-lamp biomicroscopy, dilated fundus examination, Goldmann applanation tonometry, infrared pupillometry (Neuroptics, Irvine, CA, USA), computerized corneal topography, and wavefront aberrometry using the WaveScan ${ }^{\circledR}$ (Abbott Medical Optics).

All surgeries were performed at Stanford University Eye Laser Center by a single surgeon (EEM). Topical proparacaine hydrochloride $0.5 \%$ (Ophthetic), moxifloxacin hydrochloride ophthalmic solution $0.5 \%$ (Alcon, Fort Worth, TX, USA), and ketorolac tromethamine ophthalmic solution $0.4 \%$ (Acular LS) were administered immediately before the procedure.

Flaps were created using settings consistent with the usual practice at the laser center. Specifically, flaps created using the $150 \mathrm{kHz}$ laser had a $9.0 \mathrm{~mm}$ diameter, superior hinge, $105 \mu \mathrm{m}$ programmed flap thickness, and $130^{\circ}$ inverted sidecut angle. The bed's spot and line separation was $7 \mu \mathrm{m}$, with a pulse energy of $0.75 \mu \mathrm{J}$, and the side-cut's spot and line separation was $5 \mu \mathrm{m}$, with a pulse energy of $0.75 \mu \mathrm{J}$. Flaps created using the $60 \mathrm{kHz}$ system had the same orientation and dimensions, but with a different side-cut profile of $70^{\circ}$. The bed's spot and line separation was $7 \mu \mathrm{m}$, with a pulse energy of $1.0 \mu \mathrm{J}$, and the side-cut's spot and line separation was $5 \mu \mathrm{m}$, with a pulse energy of $1.0 \mu \mathrm{J}$.

Bilateral flaps were made before refractive treatment with the Customvue S4 IR excimer laser system (Abbott Medical Optics). To eliminate a potential effect from second eye surgery, an equal number of patients had their first flap made with the $60 \mathrm{kHz}$ and $150 \mathrm{kHz}$ femtosecond lasers. Flaps were marked for alignment, lifted, and repositioned manually after the ablation treatment. Postoperative medications were topical 
moxifloxacin (Vigamox) four times daily for 4 days and prednisolone acetate $1.0 \%$ (Predforte) four times daily for 7 days.

\section{Measurement of self-reported quality of vision}

Patients completed the QoV questionnaire, which is a validated, Rasch-tested, linear-scaled 30-item instrument developed by McAlinden et al, ${ }^{6}$ who consider it suitable for measuring $\mathrm{QoV}$ in patients with all types of refractive correction, eye surgery, and eye disease. The instrument measures ten parameters along with the three subscales in terms of symptom frequency, severity, and the degree to which the symptom is bothersome. Each subscale comprises a question, which is answered by the patient, and has a score ranging from 0 , indicating never or not at all, to 3 , indicating very often or severe (Table 1). Scores for each question are summed into a composite score; higher composite scores indicate poorer QoV. The parameters measured by the instrument are glare, haloes, starbursts, hazy vision, blurred vision, distortion, double or multiple images, fluctuation in vision, focusing difficulties, and difficulties judging distance or depth perception. The first seven of these parameters are paired with an image chosen by the authors of the instrument to reduce the possibility of inconsistent responses. The instrument was administered in a bilateral simultaneous fashion preoperatively and at 1, 3, 6, and 12 months after LASIK.

\section{Statistics}

Statistical analyses were performed with commercially available software packages (SPSS for Mac, version 20.0; SPSS, Inc., Chicago, IL, USA and Stata for Mac, version 13.0; StataCorp LP, College Station, TX, USA). Normal distribution was assessed with the Shapiro-Wilk test. Comparisons of means were performed using a paired test; normally distributed data were analyzed with a paired $t$-test, and nonnormally distributed data were analyzed with a Wilcoxon signed-rank test, which is the nonparametric analog of the paired $t$-test. Correlations between binary variables were calculated using

Table I Quality of vision questionnaire

\begin{tabular}{|c|c|}
\hline Parameter & Subscale question and response scale \\
\hline \multirow[t]{3}{*}{ Glare } & I. How often do you experience glare? Never (0) - Very often (3) \\
\hline & 2. How severe is the glare? Not at all $(0)-$ Severe $(3)$ \\
\hline & 3. How bothersome is the glare? Not at all (0) - Very (3) \\
\hline \multirow[t]{3}{*}{ Haloes } & 4. How often do you experience haloes? Never (0) - Very often (3) \\
\hline & 5. How severe are the haloes? Not at all $(0)-$ Severe (3) \\
\hline & 6. How bothersome are the haloes? Not at all $(0)-$ Severe $(3)$ \\
\hline \multirow[t]{3}{*}{ Starbursts } & 7. How often do you experience starbursts? Never (0) - Very often (3) \\
\hline & 8. How severe are the starbursts? Not at all $(0)-$ Severe $(3)$ \\
\hline & 9. How bothersome are the starbursts? Not at all (0) - Severe (3) \\
\hline \multirow[t]{3}{*}{ Hazy vision } & I0. How often do you experience hazy vision? Never (0) - Very often (3) \\
\hline & II. How severe is the hazy vision? Not at all $(0)-$ Severe $(3)$ \\
\hline & 12. How bothersome is the hazy vision? Not at all $(0)-$ Severe (3) \\
\hline \multirow[t]{3}{*}{ Blurred vision } & 13. How often do you experience blurred vision? Never (0) - Very often (3) \\
\hline & 14. How severe is the blurred vision? Not at all $(0)$ - Severe (3) \\
\hline & 15. How bothersome is the blurred vision? Not at all $(0)-$ Severe (3) \\
\hline \multirow[t]{3}{*}{ Distortion } & 16. How often do you experience distortion? Never (0) - Very often (3) \\
\hline & 17. How severe is the distortion? Not at all (0) - Severe (3) \\
\hline & 18. How bothersome is the distortion? Not at all $(0)$ - Severe (3) \\
\hline \multirow[t]{3}{*}{ Double or multiple images } & 19. How often do you experience double or multiple images? Never (0) - Very often (3) \\
\hline & 20. How severe are the double or multiple images? Not at all $(0)-$ Severe $(3)$ \\
\hline & 2I. How bothersome are the double or multiple images? Not at all $(0)$ - Severe (3) \\
\hline \multirow[t]{3}{*}{ Fluctuation in your vision } & 22. How often do you experience fluctuation in your vision? Never (0) - Very often (3) \\
\hline & 23. How severe is the fluctuation in your vision? Not at all $(0)-$ Severe $(3)$ \\
\hline & 24. How bothersome is the fluctuation in your vision? Not at all $(0)-$ Severe (3) \\
\hline \multirow[t]{3}{*}{ Focusing difficulties } & 25. How often do you experience focusing difficulties? Never (0) - Very often (3) \\
\hline & 26. How severe are the focusing difficulties? Not at all (0) - Severe (3) \\
\hline & 27. How bothersome are the focusing difficulties? Not at all $(0)-$ Severe $(3)$ \\
\hline Difficulties judging distance & 28. How often do you have difficulty judging distance or depth perception? Never (0) - Very often (3) \\
\hline \multirow[t]{2}{*}{ or depth perception } & 29. How severe are the difficulties judging distance or depth perception? Not at all $(0)-$ Severe (3) \\
\hline & 30. How bothersome are the difficulties judging distance or depth perception? Not at all $(0)-$ Severe (3) \\
\hline
\end{tabular}

Notes: The QoV questionnaire is a Rasch-tested, linear-scaled (0-3) 30-item instrument on three scales providing a QoV score in terms of symptom frequency, severity, and the degree to which the symptom is bothersome. McAlinden et $\mathrm{al}^{6}$ developed the instrument and consider it suitable for measuring QoV in patients with all types of refractive correction, eye surgery, and eye disease. The instrument and further details pertaining to its development can be found in McAlinden et al. ${ }^{6}$ Abbreviation: QoV, quality of vision. 
Pearson's chi-square test. $P$-values were two-sided and considered statistically significant when less than 0.05 .

\section{Results}

One hundred and twenty eyes of 60 patients were enrolled in the study. The mean age of the patients was $34.3 \pm 9.0$ years, and $63.9 \%$ of the cohort was female. Preoperative data showed no statistically significant differences between the groups in all studied parameters, including corrected distance visual acuity, manifest sphere and cylinder, manifest spherical equivalent, coma, trefoil, spherical aberration, and root mean square error (all $P>0.05$, Table 2). There was also no statistically significant difference in the proportion of distance dominant eyes randomized to the iFS $150 \mathrm{kHz}$ laser $(P=0.86)$. There were no intraoperative or postoperative complications.

None of the QoV parameters exhibited statistically significant differences preoperatively or at postoperative Months 1, 3, 6, and 12. Most parameters exhibited parallel trends of stability between the groups or statistically insignificant improvement between the preoperative and 12-month follow-up, with the exception of hazy vision and vision fluctuation. For the latter questionnaire parameters, there were different trends in each group, but they were small and statistically insignificant. For the Bothersome subscale of Hazy Vision, the mean rating improved (ie, decreased) between the preoperative and 12-month assessments in the FS $60 \mathrm{kHz}$ group, whereas it worsened (ie, increased) in the iFS $150 \mathrm{kHz}$ group. For the Frequency subscale of Vision Fluctuation, the FS 60 kHz group's mean improved over 1 year, whereas the iFS $150 \mathrm{kHz}$ group's mean remained stable. Similarly, for the Severity subscale of Vision Fluctuation, the FS $60 \mathrm{kHz}$ group's mean improved, whereas the iFS $150 \mathrm{kHz}$ group's mean worsened. However, none of these trends were statistically significant (all $P>0.05$, Figures 2 and 3; Table 3).

\section{Discussion}

QoV after refractive surgery is an area of growing interest. ${ }^{7-10}$ We conducted a prospective, comparative fellow eye study of 120 eyes in 60 patients who underwent femtosecond-assisted myopic LASIK to evaluate the effect of two different laser systems on QoV using the QoV questionnaire. ${ }^{6}$ To the best of our knowledge, this is the first clinical study to compare femtosecond laser systems on the basis of self-reported QoV.

This study is a companion to three other investigations that have recently been published by our group, all of which have compared the FS $60 \mathrm{kHz}$ to the iFS $150 \mathrm{kHz}$ femtosecond lasers in fellow eyes of the same cohort of patients. ${ }^{4,5,11}$ The first study by Kung et $\mathrm{al}^{5}$ focused on the advanced sidecut capabilities of the iFS $150 \mathrm{kHz}$ system, comparing a $130^{\circ}$ inverted profile to a conventional $70^{\circ}$ profile made with the FS $60 \mathrm{kHz}$ system. The study found a significantly faster recovery of corneal sensation in eyes with an inverted side-cut without a corresponding improvement in self-reported dry eye symptoms; it was limited by omission of a standardized assessment of the ocular surface for dryness, which may or may not have had a stronger correlation with esthesiometry. ${ }^{6}$ Yu and Manche ${ }^{4}$ subsequently published a second study of the same cohort that observed a short-term advantage in

Table 2 Cohort demographics and preoperative clinical parameters

\begin{tabular}{|c|c|c|c|}
\hline \multirow[t]{2}{*}{ Parameter } & \multicolumn{2}{|l|}{ Mean \pm SD $($ range $)$ or $\%(95 \% \mathrm{Cl})$} & \multirow[t]{2}{*}{$P$-value ${ }^{a}$} \\
\hline & $\begin{array}{l}130^{\circ} \text { inverted side cut made by } \\
\text { a } 150 \mathrm{kHz} \text { femtosecond laser }\end{array}$ & $\begin{array}{l}70^{\circ} \text { conventional side-cut made } \\
\text { by a } 60 \mathrm{kHz} \text { femtosecond laser }\end{array}$ & \\
\hline \multicolumn{4}{|l|}{ Demographics } \\
\hline Age, years & $34.3 \pm 9.0(21$ to 75$)$ & & \\
\hline Female & $63.9 \%(51.0$ to 76.8$)$ & & \\
\hline Right eye & $59.0 \%$ (45.8 to 72.2$)$ & $41.0 \%(27.8$ to 54.2$)$ & $0.05^{b}$ \\
\hline Dominant eye & $50.8 \%(37.4$ to 64.2$)$ & $49.2 \%(35.8$ to 62.6$)$ & $0.86^{\mathrm{b}}$ \\
\hline \multicolumn{4}{|c|}{ Preoperative clinical parameters } \\
\hline CDVA (logMAR) & $-0.14 \pm 0.07(-0.30$ to 0.00$)$ & $-0.14 \pm 0.07(-0.20$ to 0.00$)$ & 0.82 \\
\hline Manifest sphere & $-4.62 \pm 2.32(-9.75$ to -1.00$)$ & $-4.66 \pm 2.30(-10.00$ to -0.75$)$ & 0.73 \\
\hline Manifest cylinder & $+0.65 \pm 0.49(0.00$ to 1.75$)$ & $+0.69 \pm 0.70(0.00$ to 3.00$)$ & 0.57 \\
\hline Manifest SE & $-4.30 \pm 2.31$ ( -9.75 to -0.88$)$ & $-4.32 \pm 2.31$ ( $(-10.00$ to -0.75$)$ & 0.85 \\
\hline Coma & $0.19 \pm 0.10(0.05$ to 0.45$)$ & $0.18 \pm 0.09(0.03$ to 0.44$)$ & 0.33 \\
\hline Trefoil & $0.16 \pm 0.09(0.02$ to 0.45$)$ & $0.17 \pm 0.08(0.01$ to 0.35$)$ & 0.55 \\
\hline Spherical aberration & $0.09 \pm 0.12(-0.19$ to 0.40$)$ & $0.09 \pm 0.12(-0.26$ to 0.35$)$ & 0.79 \\
\hline RMS error & $0.34 \pm 0.11(0.17$ to 0.58$)$ & $0.34 \pm 0.09(0.1 \mathrm{I}$ to 0.58$)$ & 0.61 \\
\hline
\end{tabular}

Notes: a $P$-values are calculated using the paired $t$-test unless otherwise specified; ${ }^{b}$-values are calculated using the Pearson's chi-square test.

Abbreviations: CDVA, corrected distance visual acuity; $\mathrm{Cl}$, confidence interval; logMAR, logarithm of the minimum angle of resolution; RMS, root mean square; SD, standard deviation; SE, spherical equivalent. 


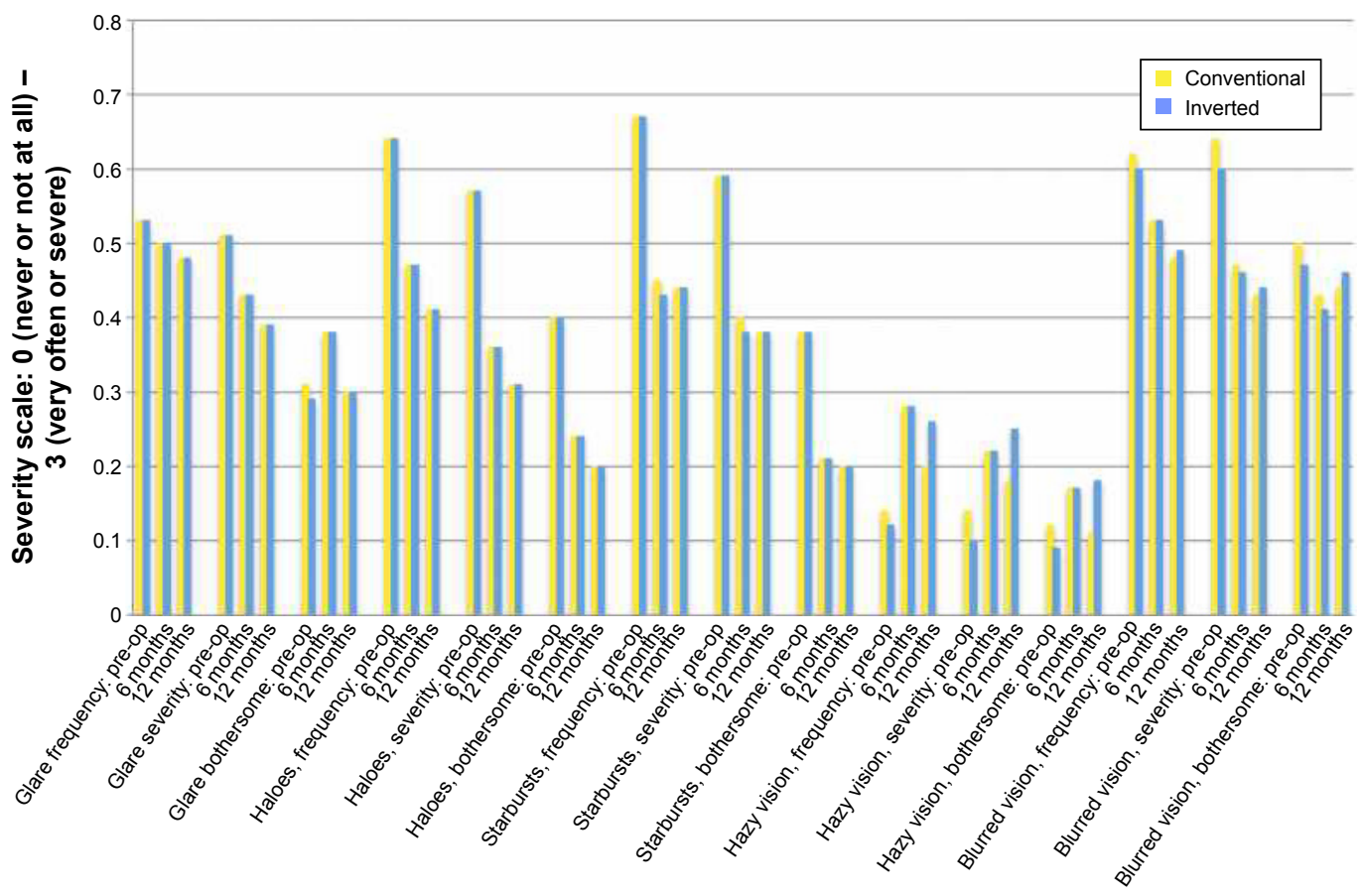

Survey parameter

Figure 2 Self-reported QoV outcomes after femtosecond-assisted myopic LASIK with either a $130^{\circ}$ inverted side-cut made with a $150 \mathrm{kHz}$ laser or a $70^{\circ}$ conventional side cut made with a $60 \mathrm{kHz}$ laser (QoV items I-15).

Note: All $P>0.05$.

Abbreviations: QoV, quality of vision; LASIK, laser-assisted in situ keratomileusis; pre-op, pre-operative.

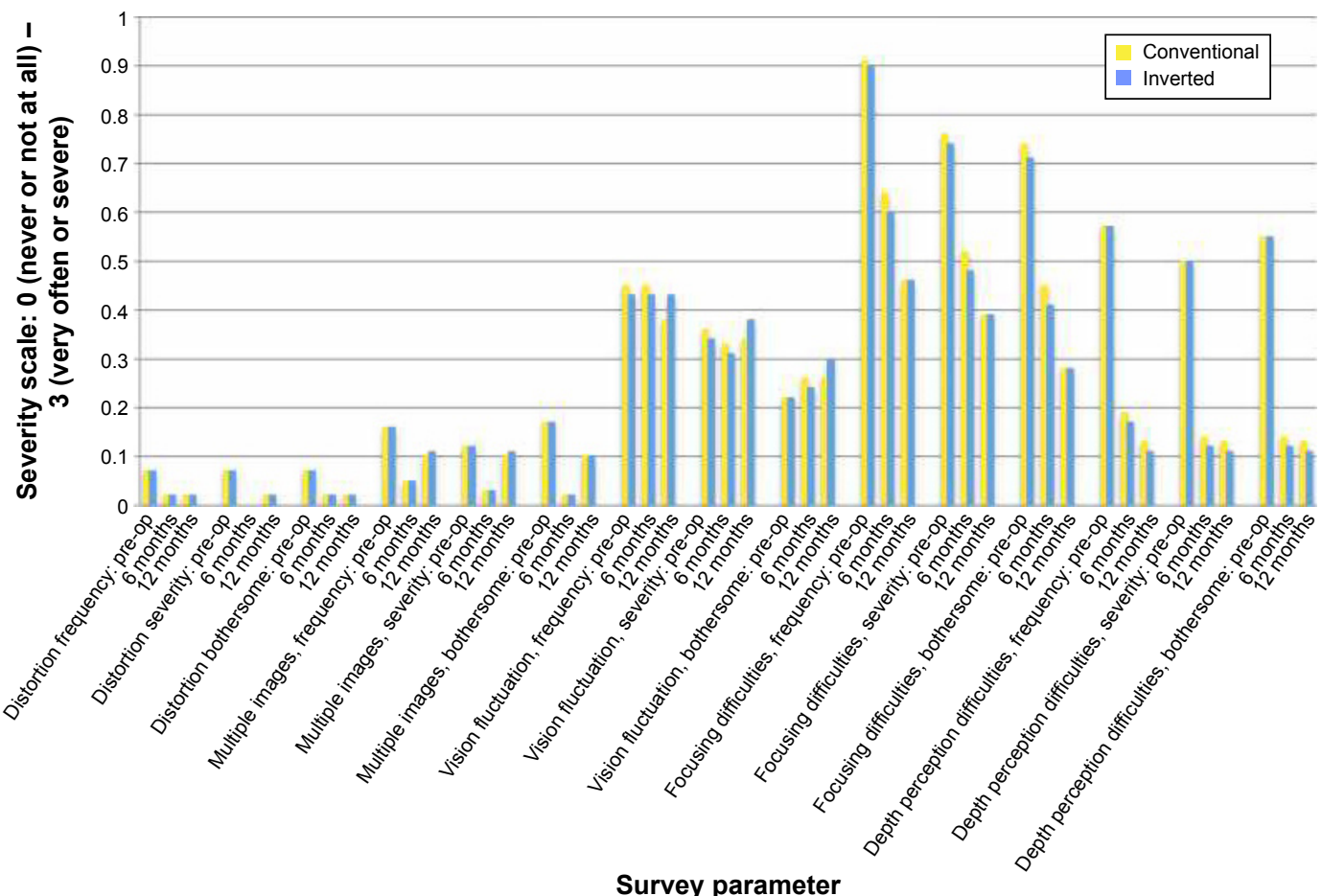

Figure 3 Self-reported QoV outcomes after femtosecond-assisted myopic LASIK with either a $130^{\circ}$ inverted side-cut made with a $150 \mathrm{kHz}$ laser or a $70^{\circ}$ conventional side-cut made with a $60 \mathrm{kHz}$ laser (QoV items 16-30).

Note: All $P>0.05$.

Abbreviations: QoV, quality of vision; LASIK, laser-assisted in situ keratomileusis; pre-op, pre-operative. 


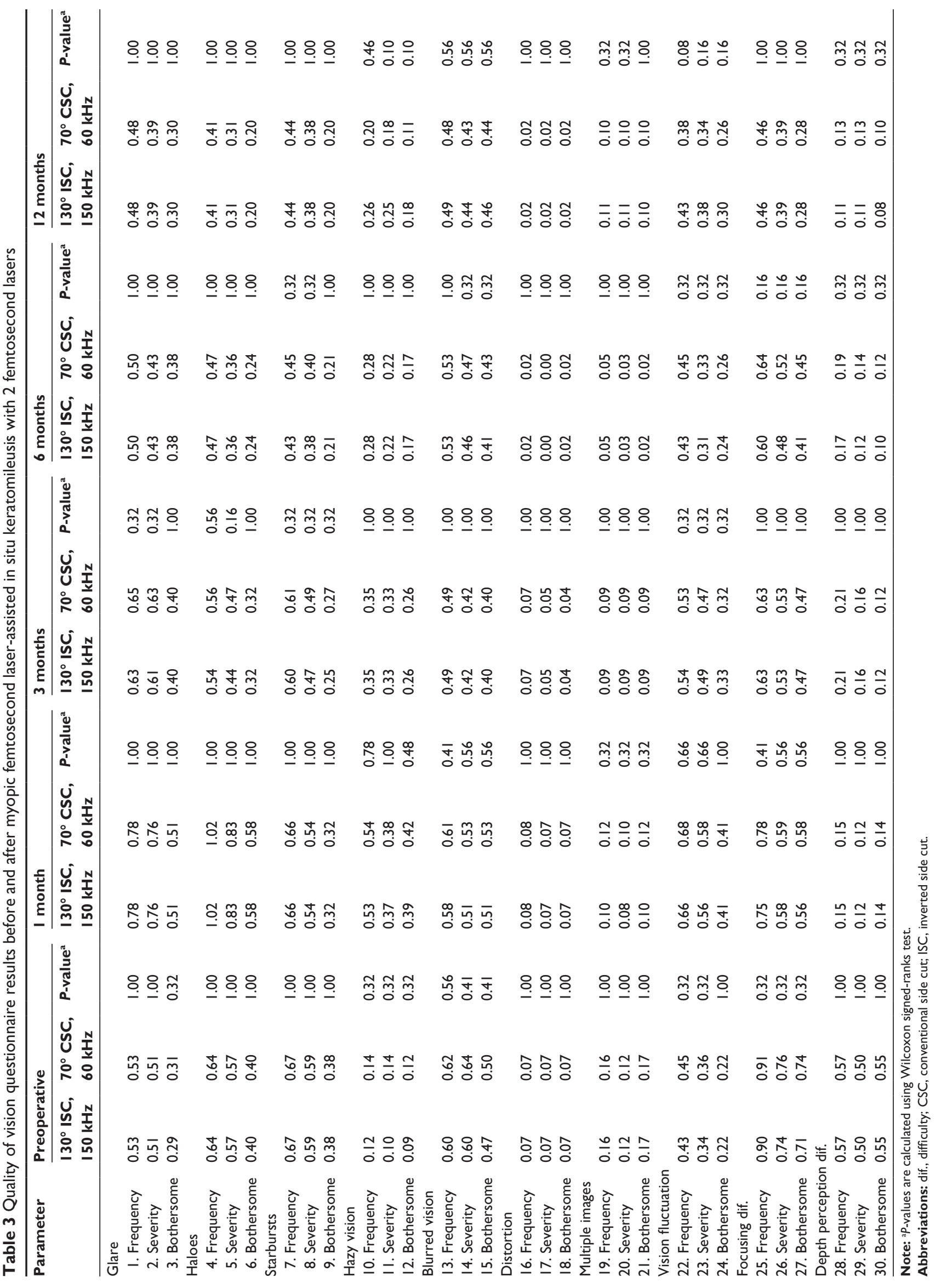


UDVA conferred by the iFS $150 \mathrm{kHz}$ that was present at 1 week ( $85 \%$ vs $71 \%$ achieved $20 / 16$ or better, $P<0.05$ ) but absent thereafter up to the study's 1-year follow-up. All other parameters, including contrast sensitivity and higher-order aberrations, were also equivalent between the lasers. Finally, $\mathrm{Yu}$ and Manche ${ }^{11}$ published a third study of this cohort that showed equivalence between the laser platforms with respect to flap thickness accuracy and uniformity.

As they pertain to this study, the substantive differences between the FS $60 \mathrm{kHz}$ and iFS $150 \mathrm{kHz}$ lasers are the pulse frequency (60 vs $150 \mathrm{kHz}$ ), the energy per pulse $(1.0 \mathrm{vs}$ $0.75 \mu \mathrm{J})$, and the side-cut angle of the flap $\left(70^{\circ}\right.$ vs $\left.130^{\circ}\right)$. It is known from histopathologic and confocal studies that higher frequency, lower energy pulses cause less tissue necrosis and render a smoother stromal bed compared to lower frequency, higher energy pulses. ${ }^{2,12}$ Thus, at least in theory, one could reasonably postulate that the iFS $150 \mathrm{kHz}$ system might improve visual outcomes after LASIK.

The results published by Yu and Manche ${ }^{11}$ showing faster recovery of UDVA at 1 week with the iFS $150 \mathrm{kHz}$ laser may support such a postulate, but it also raises compelling questions about why the advantage was not retained at subsequent follow-ups. Was the initial superiority of UDVA delivered by the iFS $150 \mathrm{kHz}$ laser due to less inflammation and a smoother interface from its lower pulse energy, or was it due to a more regular ocular surface and/or a more stable flap from its inverted side-cut?

The possibility that there was less inflammation in the iFS group is reasonable in light of the known decrement in UDVA associated with diffuse lamellar keratitis (DLK) in the immediate postoperative period. ${ }^{13}$ Choe et al ${ }^{14}$ showed equivalent frequencies of DLK in eyes with flaps made by the FS $15 \mathrm{kHz}$, FS $30 \mathrm{kHz}$, and FS $60 \mathrm{kHz}$ systems, but others have shown increased risk of DLK in a comparison between the FS $60 \mathrm{kHz}$ laser and the Femto LDV laser, which has a repetition rate faster than $5 \mathrm{mHz} .{ }^{15}$ However, Yu and Manche ${ }^{11}$ reported no instances of DLK in their series, making this possibility moot.

A smoother interface is another potential explanation, with the caveat that perhaps a "rougher" stromal interface rendered by the slower FS $60 \mathrm{kHz}$ system smoothens over time due to remodeling. ${ }^{16}$ Were this true, it might explain the trend toward equivalence of UDVA between the FS $60 \mathrm{kHz}$ and iFS $150 \mathrm{kHz}$ systems 1 year after an initial advantage in the latter group. Supporting this explanation are the handful of studies that have confirmed through masked observation that stromal beds are indeed smoother with lower pulse energies delivered by a higher frequency laser. ${ }^{1,17}$
There are also data substantiating the premise that pulse energy may have a threshold effect on bed smoothness. A study by Kymionis et al ${ }^{17}$ showed that the iFS $150 \mathrm{kHz}$ laser delivered equivalent smoothness compared to the Wavelight FS $200 \mathrm{kHz}$ laser, suggesting that above a certain frequency (and below a certain pulse energy), there are diminishing effects on the stromal bed and flap interface. By contrast, a study by Sarayba et $\mathrm{al}^{1}$ showed a smoother stromal surface with a $30 \mathrm{kHz}$ laser (1.2 $\mu \mathrm{J}$ raster energy) compared to a $15 \mathrm{kHz}$ laser ( $2 \mu \mathrm{J}$ raster energy). A difference of only $0.25 \mu \mathrm{J}$ between the laser systems studied in the present investigation could certainly contribute to an explanation of why there might be no observed difference in QoV.

The observation from the study by Kung et $\mathrm{al}^{5}$ that an inverted side-cut made with the iFS $150 \mathrm{kHz}$ laser conferred faster recovery of sensation without an improvement in dry eye symptoms may also partially explain the absence of a difference in QoV compared to the FS $60 \mathrm{kHz}$ laser. Dry eye is associated with impaired functional visual acuity as well as decreased QoV, ${ }^{18-20}$ and is one of the most common side effects of LASIK surgery. Multiple studies have implicated disrupted corneal sensation as the culprit behind post-LASIK dry eye. ${ }^{21-24}$ Severing corneal nerves when cutting the LASIK flap disrupts neurosensory feedback for tear formation and osmolarity homeostasis, which, in turn, causes neurotrophic corneal epitheliopathy. ${ }^{25,26}$ LASIK flaps made with a femtosecond laser have been associated with decreased dry eye and longer tear break up times compared to flaps made with a microkeratome. ${ }^{27-29}$ However, the negative findings of the present study suggest that even if superior side cut architecture does indeed provide improved wound healing and ocular surface homeostasis, these biomechanical advantages may not translate to improved subjective QoV. The latter postulate agrees with the conclusions made by prior studies, which have not demonstrated consistent associations between objective and subjective correlates of dry eye following LASIK. ${ }^{30,31}$

Results from the study by Kung et $\mathrm{al}^{5}$ also raise the possibility of an alternative explanation to the faster recovery of UDVA in the iFS $150 \mathrm{kHz}$ group and absence of any difference in QoV - biomechanical flap stability. A more stable and anatomically positioned flap conferred by the inverted side-cut ${ }^{32,33}$ might be the best explanation for faster visual recovery with the iFS $150 \mathrm{kHz}$ laser at 1 week; however, this postulate requires further investigation. Future studies should control for the effect of frequency and pulse energy by comparing the $70^{\circ}$ side-cuts made with the iFS $150 \mathrm{kHz}$ to the $130^{\circ}$ side-cuts made with the same laser. The iFS 
$150 \mathrm{kHz}$ system should also be compared to the FS $60 \mathrm{kHz}$ system using a $70^{\circ}$ side-cut to ascertain the effect of a $0.25 \mu \mathrm{J}$ difference in pulse energy with a frequency difference of $90 \mathrm{kHz}$. In all these studies, the ocular surface must be controlled for with systematized grading of superficial punctate keratopathy and tear film, which were not controlled for in any of our group's comparative studies of the iFS $150 \mathrm{kHz}$ and $\mathrm{FS} 60 \mathrm{kHz}$ lasers to date.

The most important strength of this study is that it randomized contralateral eyes in the same individual because fellow eyes are more likely to demonstrate similar corneal biomechanical properties and wound healing as compared to eyes from different individuals. Other strengths of this study are the length of prospective follow-up to 1 year and the use of a validated Rasch-tested measuring instrument to evaluate self-reported QoV. The obvious limitation to consider is the use of different laser platforms - the $60 \mathrm{kHz}$ IntraLase FS was used for the $70^{\circ}$ side-cut, while the $150 \mathrm{kHz}$ IntraLase iFS was used for the $130^{\circ}$ inverted side-cut. On the other hand, comparing these two platforms is likely more reflective of the real-world progression faced by refractive surgeons considering newer technologies. Finally, it is possible that our measuring instrument was insufficiently sensitive to resolve differences between the two eyes and that the study was inadequately powered to detect significance for the QoV parameters. Recall bias may have also affected the results, with the majority of patients tending to select the same answer for both eyes as well as give positive ratings in accordance with general satisfaction with their improved UDVA.

\section{Conclusion}

In summary, we found that a $130^{\circ}$ inverted side cut LASIK flap made with a $0.25 \mu \mathrm{J}$ lower pulse energy using the iFS $150 \mathrm{kHz}$ laser was not associated with any statistically significant differences in self-reported QoV as measured by the QoV questionnaire over 12 months of follow-up compared to a conventional $70^{\circ}$ side cut made with the FS $60 \mathrm{kHz}$ laser.

\section{Acknowledgment}

Abbott Medical Optics, Inc. provided an unrestricted grant to partially fund this clinical trial.

\section{Disclosure}

EEM: Equity in Calhoun Vision, Inc., Krypton Vision, Seros Medical, LLC, and Veralas and was a consultant for Best Doctors, Gerson Lehrman. The authors report no other conflicts of interest in this work.

\section{References}

1. Sarayba MA, Ignacio TS, Binder PS, Tran DB. Comparative study of stromal bed quality by using mechanical, IntraLase femtosecond laser 15- and 30-kHz microkeratomes. Cornea. 2007;26:446-451.

2. Serrao S, Buratto L, Lombardo G, De Santo MP, Ducoli P, Lombardo M. Optimal parameters to improve the interface quality of the flap bed in femtosecond laser-assisted laser in situ keratomileusis. $J$ Cataract Refract Surg. 2012;38:1453-1459.

3. Netto MV, Mohan RR, Medeiros FW, et al. Femtosecond laser and microkeratome corneal flaps: comparison of stromal wound healing and inflammation. J Refract Surg. 2007;23:667-676.

4. Yu CQ, Manche EE. Comparison of 2 femtosecond lasers for flap creation in myopic laser in situ keratomileusis: one-year results. J Cataract Refract Surg. 2015;41:740-748.

5. Kung JS, Sales CS, Manche EE. Corneal sensation and dry eye symptoms after conventional versus inverted side-cut femtosecond LASIK: a prospective randomized study. Ophthalmology. 2014;121:2311-2316.

6. McAlinden C, Pesudovs K, Moore JE. The development of an instrument to measure quality of vision: the Quality of Vision (QoV) questionnaire. Invest Ophthalmol Vis Sci. 2010;51:5537-5545.

7. He L, Liu A, Manche EE. Wavefront-guided versus wavefront-optimized laser in situ keratomileusis for patients with myopia: a prospective randomized contralateral eye study. Am J Ophthalmol. 2014;157: 1170-1178.e1.

8. Murakami Y, Manche EE. Prospective, randomized comparison of self-reported postoperative dry eye and visual fluctuation in LASIK and photorefractive keratectomy. Ophthalmology. 2012;119:2220-2224.

9. Sales CS, Manche EE. One-year outcomes from a prospective, randomized, eye-to-eye comparison of wavefront-guided and wavefrontoptimized LASIK in myopes. Ophthalmology. 2013;120:2396-2402.

10. Yu CQ, Manche EE. Comparison of 2 wavefront-guided excimer lasers for myopic laser in situ keratomileusis: one-year results. J Cataract Refract Surg. 2014;40:412-422.

11. Yu CQ, Manche EE. A comparison of LASIK flap thickness and morphology between the Intralase $60-$ and $150-\mathrm{kHz}$ femtosecond lasers. $J$ Refract Surg. 2014;30:827-830.

12. Santhiago MR, Wilson SE. Cellular effects after laser in situ keratomileusis flap formation with femtosecond lasers: a review. Cornea. 2012;31:198-205.

13. de Paula FH, Khairallah CG, Niziol LM, Musch DC, Shtein RM. Diffuse lamellar keratitis after laser in situ keratomileusis with femtosecond laser flap creation. J Cataract Refract Surg. 2012;38:1014-1019.

14. Choe CH, Guss C, Musch DC, Niziol LM, Shtein RM. Incidence of diffuse lamellar keratitis after LASIK with $15 \mathrm{KHz}, 30 \mathrm{KHz}$, and $60 \mathrm{KHz}$ femtosecond laser flap creation. J Cataract Refract Surg. 2010;36: 1912-1918.

15. Tomita M, Sotoyama Y, Yukawa S, Nakamura T. Comparison of DLK incidence after laser in situ keratomileusis associated with two femtosecond lasers: Femto LDV and IntraLase FS60. Clin Ophthalmol. 2013; 7:1365-1371.

16. Esquenazi S, Esquenazi I, Grunstein L, He J, Bazan H. Immunohistological evaluation of the healing response at the flap interface in patients with LASIK ectasia requiring penetrating keratoplasty. J Refract Surg. 2009;25:739-746.

17. Kymionis GD, Kontadakis GA, Naoumidi I, et al. Comparative study of stromal bed of LASIK flaps created with femtosecond lasers (IntraLase FS150, WaveLight FS200) and mechanical microkeratome. Br J Ophthalmol. 2014;98:133-137.

18. Goto E, Yagi Y, Matsumoto Y, Tsubota K. Impaired functional visual acuity of dry eye patients. Am J Ophthalmol. 2002;133:181-186.

19. Toda I, Yoshida A, Sakai C, Hori-Komai Y, Tsubota K. Visual performance after reduced blinking in eyes with soft contact lenses or after LASIK. J Refract Surg. 2009;25:69-73.

20. Habay T, Majzoub S, Perrault O, Rousseau C, Pisella PJ. [Objective assessment of the functional impact of dry eye severity on the quality of vision by double-pass aberrometry]. J Fr Ophtalmol. 2014;37:188-194. French. 
21. Darwish T, Brahma A, O’Donnell C, Efron N. Subbasal nerve fiber regeneration after LASIK and LASEK assessed by noncontact esthesiometry and in vivo confocal microscopy: prospective study. J Cataract Refract Surg. 2007;33:1515-1521.

22. Stern ME, Beuerman RW, Fox RI, Gao J, Mircheff AK, Pflugfelder SC. The pathology of dry eye: the interaction between the ocular surface and lacrimal glands. Cornea. 1998;17:584-589.

23. Quinto GG, Camacho W, Behrens A. Postrefractive surgery dry eye. Curr Opin Ophthalmol. 2008;19:335-341.

24. Calvillo MP, McLaren JW, Hodge DO, Bourne WM. Corneal reinnervation after LASIK: prospective 3-year longitudinal study. Invest Ophthalmol Vis Sci. 2004;45:3991-3996.

25. Gilbard JP, Gray KL, Rossi SR. A proposed mechanism for increased tear-film osmolarity in contact lens wearers. Am J Ophthalmol. 1986; 102:505-507.

26. Lambiase A, Rama P, Aloe L, Bonini S. Management of neurotrophic keratopathy. Curr Opin Ophthalmol. 1999;10:270-276.

27. Patel SV, McLaren JW, Kittleson KM, Bourne WM. Subbasal nerve density and corneal sensitivity after laser in situ keratomileusis: femtosecond laser vs mechanical microkeratome. Arch Ophthalmol. 2010; 128:1413-1419.
28. Salomao MQ, Ambrosio R Jr, Wilson SE. Dry eye associated with laser in situ keratomileusis: mechanical microkeratome versus femtosecond laser. J Cataract Refract Surg. 2009;35:1756-1760.

29. Sun CC, Chang CK, Ma DH, et al. Dry eye after LASIK with a femtosecond laser or a mechanical microkeratome. Optom Vis Sci. 2013;90: 1048-1056.

30. Hovanesian JA, Shah SS, Maloney RK. Symptoms of dry eye and recurrent erosion syndrome after refractive surgery. J Cataract Refract Surg. 2001;27:577-584

31. Albietz JM, Lenton LM, McLennan SG. Effect of laser in situ keratomileusis for hyperopia on tear film and ocular surface. J Refract Surg. 2002;18:113-123.

32. Knorz MC, Vossmerbaeumer U. Comparison of flap adhesion strength using the Amadeus microkeratome and the IntraLase iFS femtosecond laser in rabbits. J Refract Surg. 2008;24:875-878.

33. Knox Cartwright NE, Tyrer JR, Jaycock PD, Marshall J. Effects of variation in depth and side cut angulations in LASIK and thin-flap LASIK using a femtosecond laser: a biomechanical study. J Refract Surg. 2012 28:419-425.
Clinical Ophthalmology

\section{Publish your work in this journal}

Clinical Ophthalmology is an international, peer-reviewed journa covering all subspecialties within ophthalmology. Key topics include: Optometry; Visual science; Pharmacology and drug therapy in eye diseases; Basic Sciences; Primary and Secondary eye care; Patien Safety and Quality of Care Improvements. This journal is indexed on

Submit your manuscript here: http://www.dovepress.com/clinical-ophthalmology-journal

\section{Dovepress}

PubMed Central and CAS, and is the official journal of The Society of Clinical Ophthalmology (SCO). The manuscript management system is completely online and includes a very quick and fair peer-review system, which is all easy to use. Visit http://www.dovepress.com/ testimonials.php to read real quotes from published authors. 